\title{
The effect of oral health educational pictures and video on periodontal health and behavior of school children
}

\author{
Athraa A. Mahmood \\ $B D S, M S c$, Assistant Lecturer, Department of Periodontal Dentistry, College of Dentistry, University of Al-Mustansiriyah.
}

\begin{abstract}
Background: Oral health education for students is a fundamental role for maintaining and raising perfect oral health and preventing oral diseases in future. This study was performed to evaluate the effect of oral health educational pictures and video on periodontal health and behavior in dentition of 12-years old school children in Baghdad city.

Materials and methods: Oral examination was conducted on (128) children of (Al-Yamama) primary school in Baghdad city. They were divided into four equal groups, each one consisting of (32) children. The first oral examination was done in first visit to children (pre-test). The community periodontal index (CPITN) scores were used to evaluate periodontal health status of children. Then, the first and second groups, experimental groups, were received instruction about oral health enhancement with educational program (pictures and video clip) regularly for one month. The third and fourth groups, control groups, were received instruction about oral health enhancement only regularly for one month. The second oral examination was done after one month to children (post-test). Also, questionnaire were given to assess oral health behaviors of children in pre- and post- tests.

Results: Clinical examination display that CPITN of experimental groups $(1,2)$ was lower with healthier gingiva when compared with control groups $(3,4)$ with statistical significant differences between pre and post-tests (P-value $<0.005)$. The percentages of using tooth brush and paste, frequency of teeth cleaning at day, time taking for cleaning teeth, preferable time of cleaning, brushing technique, tooth brush replacement, cause of tooth brushing and using of dental floss were improved in post-test in all groups in comparison with pre-test especially in the experimental groups $(1,2)$.

Conclusion: Results of this study clearly reflect the proposed positive effect of the educational program in the lowering CPITN indices scores among the participants in the experimental group. Results of this study also provide another clue that combination of instruction about oral health enhancement with educational program (pictures and video clip) that represent new strategies for community oral health education; which could be targeted in order to enhance the effect of the oral health education campaigns directed to primary school children.
\end{abstract}

KEYWORDS

Oral pictures, video, gingivitis, CPITN, behavior.

\section{INTRODUCTION}

Dental health educational programs were developed particularly for use in schools and clinical settings. These programs utilized a range of educational methods and materials designed to enhance oral health awareness and knowledge for adoption of a non-disease lifestyle and desirable behaviors ${ }^{(1-3)}$. Bad oral health may have a deep influence on general health of the body and many oral diseases are related to persistent diseases ${ }^{(4,5)}$.

Oral health education affects the individual's oral health learning that is mandatory for optimal oral health. Oral health literacy emphasizes an availability of skills to understand and use information for suitable oral health decisions ${ }^{(6)}$. The School can supply an encouraging circumference and an ideal setting for enhancement oral health ${ }^{(7,8)}$.

Healthy periodontium plays an important role in the total oral health of the body, especially in childhood, the age when the periodontal disease (PD) may begin. During childhood a variety of biological changes take place, some of them may be considered as predisposing factors to the occurrence of the gingival and periodontal diseases (PD) as tooth eruption ${ }^{(9,10)}$.
Therefore, oral educational program for those students is a fundamental part for elevating, stabilization and maintaining ideal oral health and preventing dental and PD ${ }^{(11,12)}$.

The most efficient way to prevent oral diseases is to control them in babyhood. It is especially important to take utility of the school health program, in this program it is possible to arrive maximum number of children at an age can profound a valid oral behavior. The most effective education happen in a face to face conditions where there is open exchange of information and where greatest personal sharing in decision making occurs. Actual communication between teacher and student is important in the educational process. However it's not practical to learn each student separately since it becomes expensive and time loss. Therefore, instructions could be performed to educate a large number of students at one time. It could be done by a hygienist, dentist, a teacher or even by student from upper level ${ }^{13,14)}$.

The aims of the study was to show the effectiveness of oral health educational program (pictures and video) on behavior and periodontal health status in dentition of 12-years old school children in Baghdad city. 


\section{MATERIALS AND METHODS}

Permission was taken from appropriate authorities to conduct this study at (Al-Yamama primary school) in Baghdad city during the period from November 2015 to January 2016 on (128) children. All of them were healthy and of comparable age (11-12 years old). They were chosen on a random basis and divided into 4 equal groups; each group consisting of 32 children; groups $(1,2)$ were called experimental groups while groups $(3,4)$ were called control groups as shown in Table (1).

Two clinical examinations had been carried out to the all children during the present study; the first one carried out before the program conduction (pre-test) and the second one was done one month after (post-test). Experimental groups $(1,2)$ were received instruction about oral health enhancement with oral educational program (pictures and video clip) regularly for one month, while the control groups $(3,4)$ were received instruction about oral health enhancement only regularly for one month.

Clinical oral examination happen through school hours in class rooms under normal light. A dental mirror and a WHO periodontal probe were used. The community periodontal index (CPITN) scores were used $(0=$ healthy gums without bleeding, $1=$ with gingival bleeding, $2=$ with calculus). The presence or absence of gingival bleeding and dental plaque was recorded, also the periodontal status was recorded separately for each six index teeth $(16,11$, 26, 36, 31, and 46). Missing teeth, retained roots, gingival swelling due to carious lesion were excluded from this study ${ }^{(15)}$.

The questionnaire form was prepared and translate to Arabic language which were filled by children in first visit (pre-test) and after one month (post-test). This questionnaire was used as a mean of data collection to detect the effect of educational programs in student's practices and knowledge about information source of oral heathy which include the following:

- Cleaning teeth means (tooth brush, fingers, I don't use any mean).

- Brushing teeth (tooth paste, salts, others).

- Frequency of teeth brushing at day (one time daily, two times daily, three times daily, infrequent, never).

- Time period of brushing (less than 1 minute, 1-2 minutes, more than 2 minutes).

- Preferable time for tooth brushing (before breakfast, at bed time, after each meals).

- Brushing technique (horizontal, vertical, circular).
- Change of tooth brush (2-3 months, 4-5 months, more than 6 months).

- Reasons of tooth brushing (remove food debris and bacteria, teeth whitening, I don't know).

- Dental floss using (daily, weekly, never).

Then, all groups were given instruction about oral health enhancement. The oral health education program conduction was carried out on experimental groups $(1,2)$ only. This program was based on exposing children in these groups to pictures and video clip (CD) designed for the present study which were based on standing concepts of recommended oral health prevention ${ }^{(14,16,17)}$. Educational contents were the same in both materials (pictures, video) which contain importance of oral health, role of microbial dental plaque, technique and numbers of correct tooth-brushing and tooth flossing, importance of regular dental attention and healthy food. The video clip period lasted 15 minutes which shown in the classroom. Then, video CD was copied and distributed on each child in groups $(1,2)$ and given instructions to show it at least 2 times-weekly for about 1 month in the house.

The statistical analysis of the data was carried out by using (IBM ${ }^{\circledR}$ SPSS $^{\circledR}$ Statistics).

\section{RESULTS}

The sample was consisted of (128) children, the ages of them ranged between (11-12 years old), $50 \%$ of patients were males and $50 \%$ of patients were females (male to female ratio in this study was $1: 1$ ). Furthermore, patients were divided into four equal groups; each group consisting of 32 children; groups $(1,2)$ were called experimental groups while groups $(3,4)$ were called control groups as shown in Table (1).

The mean of CPITN was decreased in all groups (control and experimental) in post-test in comparison to pre-test; where the experimental male group (2) had heathier gingiva than other groups $(1,4,3)$ with means of CPITN scores 0.31 for group (2), 0.37 for group (1), 0.56 for group (4), 0.58 for group (3) as shown in Table (2).

The study showed elevated percentages of score (1) more than score (0) in relation to bleeding on probing in all groups in pre-test, where score 1 were $42.7 \%, 72.4 \%, 45.3 \%, 59.4 \%$ in groups $(1,2,3,4)$ respectively. While, the percentage of scores were changed toward healthy gingiva in posttest in different rates in all groups, where score (0) was elevated in all groups while scores $(1,2)$ were decreased in all groups as shown in Table (3). Also, 
the score $(0)$ was higher in experimental groups $(1,2)$ $(66.1 \%, 69.3 \%$ subsequently) than control groups (3, 4) $(51 \%, 50 \%$ subsequently) in post-test. While scores $(1,2)$ were lesser in experimental groups $(1,2)$ (score 1 was $29.7 \%, 29.2 \%$ and score 2 was $4.2 \%, 1.6 \%$ for experimental groups subsequently) than control groups $(3,4)$ (score 1 was $39.6 \%, 43.2 \%$ and score 2 was $9.4 \%, 6.8 \%$ for control groups subsequently) as shown in Table (3).

For comparisons among groups, ANOVA test was used; the results showed that there were high significant (HS) difference at P-value $\leq 0.01$ among and within groups as shown in Table (4).

Least significant difference (LSD) was performed for multiple comparisons among groups in both pre- and post-tests; the results showed that there were HS difference at $\mathrm{P}$-value $<0.01$ between group (1) pre-test and groups $(1,2,3,4)$ post-test, whereas there was non-significant (NS) difference at P-value $\geq 0.05$ between group (1) pre-test and groups $(2,3,4)$ pre-test. The group (1) post-test showed HS difference with groups $(2,3,4)$ pre-test while there was NS difference with group (2) and significant (S) difference with groups $(3,4)$ at $\mathrm{P}$-value $<0.05$ posttest. The group (2) pre-test showed HS difference with groups $(2,3,4)$ post-test while there was NS difference with groups $(3,4)$ pre-test. The group (2) post-test showed HS difference with groups $(3,4)$ pre-test and post-test. The group (3) pre-test showed there was HS difference with groups $(3,4)$ post-test while there was NS difference with group (4) pre-test. The group (3) post-test showed S difference with group (4) pre-test while there was NS difference with group (4) posttest. The group (4) pre-test showed S difference with group (4) post-test as shown in Table (5).

The using of tooth brush was higher than other means in cleaning teeth of children in post-test) in all groups. The highest rate of tooth brush was $96.9 \%$ in group (1) while the lowest rate was $78 \%$ in group (4) as shown in Table (6). Also, the using of tooth paste was higher than other materials in cleaning teeth of children in post-test. The highest rate of tooth paste was $96.9 \%$ in group (1) while the lowest rate was $78 \%$ in groups $(3,4)$ as shown in Table $(6)$.

The frequency of teeth cleaning at day (2-times) was elevated than other in all groups in post-test. The highest rate of 2-times daily was $46.9 \%$ in group (1) as shown in Table (6).

The time taken for cleaning teeth was (1-2 minutes) which was higher than other times in all groups in post-test. The highest rate of (1-2 minutes) was $71 \%$ in group (1) and lowest rate was $48 \%$ in group (4) as shown in Table (6). Also, the preferable time of cleaning at bed was the best chose by children than other times in all groups in post-test. The highest rate of bed time $56.5 \%$ in group (1) while the lowest rate was $51.4 \%$ in group (4) as shown in Table (6).

The brushing techniques (vertical and circular) were elevated after educational program (post-test) in all groups, where the highest increase reached to $55 \%$ in group (2) for vertical and $30.3 \%$ in group (1) for circular, while the least decrease reached to $52 \%$ in group (4) for vertical and $8 \%$ in group (4) for circular as shown in Table (6).

The tooth brush was replaced every (2-3 months) which was higher than other period of replacement in all groups in post-test. The highest rate was $74.2 \%$ in group (1) while the lowest rate was $68 \%$ in group (4) as shown in Table (6).

The remove of food debris and bacteria were the most reason for the tooth brushing in children in all groups in post-test. The highest rate was $90.6 \%$ in group (1) while the lowest one was $73.5 \%$ in group (4) as shown in Table (6).

The using of dental floss (daily and weekly) was elevated after educational program (post-test) in all groups, where the highest increase reached to $25.8 \%$ in group (1) for daily using and $53 \%$ in group (2) for weekly using, while the least decrease reached to $9.4 \%$ in group (3) for daily using and $18.8 \%$ in group (4) for weekly using as shown in Table (6).

\section{DISCUSSION}

This study was performed on 128 children aged (11-12) years old which is marked by acceptance of increasing responsibilities by the children including the responsibility for homework and household chores and in addition, the child can begin to assume more responsibility for oral hygiene ${ }^{(18)}$.

The sample was divided into 4 equal groups; each group consisting of 32 children; groups $(1,2)$ were called experimental groups while groups $(3,4)$ were called control groups to determine and compare oral health status and oral hygiene behavior among them by using combination of instruction about oral health enhancement with educational program.

The video has been employed as medium of oral health education to be useful and valuable visual aids. This may be attributed the fact that what's seen is usually better having a lasting impression on target population (children). The video was produced in Arabic language which serves as a culturally appropriate oral health educational tool for children (19). 
Improving the oral health status throughout a group directed periodontal health educational programs can be considered as one of the most applied strategies in field of dental and PD prevention, because it can be easily reach a large number of population and can gap the progressively enlarged shortage in the required dental manpower and financial resources especially in the developing countries ${ }^{(20,21)}$. On the other hand, children have been identified as a special group, which is at great risk of developing dental and PD. These two facts call for directing a special protection and provisions toward this age group ${ }^{(22)}$.

The current study display more healthy gingiva and less mean of CPITN in all groups in post-test in comparison to pre-test, also there was high significant difference between pre- and post-test in all groups, and this study came in agreement with other studies ${ }^{(23-25)}$ which supported the role of the educational program in promoting improve oral health in the children over a one month period. The experimental groups $(1,2)$ had healthy gingiva than control groups $(3,4)$ due to the experimental groups received combination of instruction about oral health enhancement with

Table (1): distribution of the population sample.

\begin{tabular}{|c|c|c|c|c|}
\hline \multicolumn{1}{|c|}{ Groups } & Gender & Age & No. \\
\hline & G1 & females & $11-12$ & 32 \\
\hline Experimental groups & G2 & males & $11-12$ & 32 \\
\hline Control groups & G3 & females & $11-12$ & 32 \\
\hline & G4 & males & $11-12$ & 32 \\
\hline
\end{tabular}

educational program while control groups received instructions only.

The majority of children in all groups had elevated score (1) (gingival bleeding) than score (0) (healthy gingiva) in pre-test, so that these children were needed motivation only for correction of tooth brushing to decrease the gingival bleeding and return to healthy gingiva. While, the percentage of scores were changed toward healthy gingiva in post-test in different rates in all groups. So that the application of educational program result in effective plaque control and decreases of gingival diseases in future ${ }^{(26)}$.

The changes in the oral hygiene behaviors associated with visual technologies (pictures and video clip) reinforces the impact on learning because what we see and hear has great impact on our behavior $(27,28)$.

The current study established good oral behaviors among children in all groups in post-test in comparison to pre-test especially in experimental groups that will be laid a foundation for further improvements in the children's oral health status in future ${ }^{(24)}$.

Table 2: Descriptive statistical results of CPITN scores for each group.

\begin{tabular}{|c|c|c|c|c|}
\hline \multicolumn{2}{|c|}{ Groups } & Mean & SE & SD \\
\hline \multirow{2}{*}{ G1 } & Pre-test & 0.83 & 0.08 & 0.47 \\
& Post-test & 0.37 & 0.05 & 0.31 \\
\hline \multirow{3}{*}{ G2 } & Pre-test & 0.88 & 0.05 & 0.32 \\
& Post-test & 0.31 & 0.04 & 0.24 \\
\hline \multirow{3}{*}{ G3 } & Pre-test & 0.93 & 0.07 & 0.39 \\
& Post-test & 0.58 & 0.08 & 0.45 \\
\hline \multirow{2}{*}{ G4 } & Pre-test & 0.78 & 0.05 & 0.29 \\
& Post-test & 0.56 & 0.06 & 0.35 \\
\hline
\end{tabular}

Table 3: Percentage of CPITN scores for each groups.

\begin{tabular}{|c|c|c|c|c|}
\hline \multicolumn{2}{|c|}{ Groups } & Score 0 (\%) & Score 1 (\%) & Score $2(\%)$ \\
\hline \multirow{2}{*}{ G1 } & Pre-test & 37.0 & 42.7 & 20.3 \\
\hline & Post-test & 66.1 & 29.7 & 4.2 \\
\hline \multirow{2}{*}{$\mathrm{G} 2$} & Pre-test & 19.3 & 72.4 & 8.3 \\
\hline & Post-test & 69.3 & 29.2 & 1.6 \\
\hline \multirow{2}{*}{ G3 } & Pre-test & 29.7 & 45.3 & 25.0 \\
\hline & Post-test & 51 & 39.6 & 9.4 \\
\hline \multirow{2}{*}{ G4 } & Pre-test & 31.3 & 59.4 & 9.4 \\
\hline & Post-test & 50 & 43.2 & 6.8 \\
\hline
\end{tabular}


Table 4: ANOVA test of CPITN.

\begin{tabular}{|c|c|c|c|c|c|c|}
\hline ANOVA & SS & $\mathbf{D F}$ & $\boldsymbol{M S}$ & $\boldsymbol{F}$-test & $\boldsymbol{P}$-value & Sig. \\
\hline Among groups & 12.33 & 7 & 1.76 & & & \\
\hline Within groups & 33.13 & 248 & 0.13 & 13.19 & 0.000 & $* *$ \\
\hline Total & 45.47 & 255 & & & & \\
\hline
\end{tabular}

P $\geq 0.05$ Non-Significant (NS) $\quad P<0.05$ Significant (S)* $\quad P<0.01$ High Significant (HS) * *

Table 5: LSD test to compare of CPITN among groups.

\begin{tabular}{|c|c|c|c|c|c|}
\hline \multicolumn{2}{|c|}{ Groups } & $M D$ & $S E$ & $P$-value & Sig. \\
\hline \multirow{7}{*}{ G1 pre-test } & G1 post-test & 0.45 & 0.09 & 0.000 & $* *$ \\
\hline & G2 pre-test & -0.05 & 0.09 & 0.528 & NS \\
\hline & G2 post-test & 0.51 & 0.09 & 0.000 & $* *$ \\
\hline & G3 pre-test & -0.10 & 0.09 & 0.232 & NS \\
\hline & G3 post-test & 0.24 & 0.09 & 0.007 & $* *$ \\
\hline & G4 pre-test & 0.04 & 0.09 & 0.608 & NS \\
\hline & G4 post-test & 0.26 & 0.09 & 0.004 & $* *$ \\
\hline \multirow{6}{*}{ G1 post-test } & G2 pre-test & -0.51 & 0.09 & 0.000 & $* *$ \\
\hline & $\mathrm{G} 2$ post-test & 0.05 & 0.09 & 0.528 & NS \\
\hline & G3 pre-test & -0.56 & 0.09 & 0.000 & $* *$ \\
\hline & G3 post-test & -0.20 & 0.09 & 0.027 & $*$ \\
\hline & G4 pre-test & -0.40 & 0.09 & 0.000 & $* *$ \\
\hline & G4 post-test & -0.18 & 0.09 & 0.042 & $*$ \\
\hline \multirow{5}{*}{ G2 pre-test } & G2 post-test & 0.56 & 0.09 & 0.000 & $* *$ \\
\hline & G3 pre-test & -0.05 & 0.09 & 0.573 & NS \\
\hline & G3 post-test & 0.30 & 0.09 & 0.001 & $* *$ \\
\hline & G4 pre-test & 0.10 & 0.09 & 0.253 & NS \\
\hline & G4 post-test & 0.32 & 0.09 & 0.000 & $* *$ \\
\hline \multirow{4}{*}{ G2 post-test } & G3 pre-test & -0.62 & 0.09 & 0.000 & $* *$ \\
\hline & G3 post-test & -0.26 & 0.09 & 0.005 & $* *$ \\
\hline & G4 pre-test & -0.46 & 0.09 & 0.000 & $* *$ \\
\hline & G4 post-test & -0.24 & 0.09 & 0.008 & $* *$ \\
\hline \multirow{3}{*}{ G3 pre-test } & G3 post-test & 0.35 & 0.09 & 0.000 & $* *$ \\
\hline & G4 pre-test & 0.15 & 0.09 & 0.089 & NS \\
\hline & G4 post-test & 0.37 & 0.09 & 0.000 & $* *$ \\
\hline \multirow{2}{*}{ G3 post-test } & G4 pre-test & -0.20 & 0.09 & 0.028 & $*$ \\
\hline & G4 post-test & 0.01 & 0.09 & 0.856 & NS \\
\hline G4 pre-test & G4 post-test & 0.21 & 0.09 & 0.017 & $*$ \\
\hline
\end{tabular}

P $\geq 0.05$ Non-Significant (NS) $\quad$ P $<0.05$ Significant (S)* $\quad$ P $<0.01$ High Significant (HS) * * 
Table 6: Percentages of child's behavioral in pre- and post-test.

\begin{tabular}{|c|c|c|c|c|c|c|c|c|c|}
\hline \multirow{3}{*}{\multicolumn{2}{|c|}{ Items }} & \multicolumn{8}{|c|}{ Groups } \\
\hline & & \multicolumn{2}{|c|}{ G1 } & \multicolumn{2}{|c|}{$G 2$} & \multicolumn{2}{|c|}{ G3 } & \multicolumn{2}{|c|}{ G4 } \\
\hline & & $\begin{array}{c}\text { Pre- } \\
\text { test } \\
\text { (\%) }\end{array}$ & $\begin{array}{c}\text { Post- } \\
\text { test } \\
(\%)\end{array}$ & $\begin{array}{c}\text { Pre- } \\
\text { test } \\
\text { (\%) }\end{array}$ & $\begin{array}{c}\text { Post- } \\
\text { test } \\
(\%)\end{array}$ & $\begin{array}{c}\text { Pre- } \\
\text { test } \\
\text { (\%) }\end{array}$ & $\begin{array}{c}\text { Post- } \\
\text { test } \\
\text { (\%) }\end{array}$ & $\begin{array}{c}\text { Pre- } \\
\text { test } \\
\text { (\%) }\end{array}$ & $\begin{array}{c}\text { Post- } \\
\text { test } \\
\text { (\%) }\end{array}$ \\
\hline \multirow{3}{*}{$\begin{array}{l}\text { Cleaning } \\
\text { teeth means }\end{array}$} & Tooth brush & 87.5 & 96.9 & 43.8 & 90.6 & 75 & 84.4 & 68.8 & 78.1 \\
\hline & Fingers & 6.3 & 0 & 0 & 0 & 9.4 & 6.3 & 0 & 0 \\
\hline & I don't use any mean & 6.3 & 3.1 & 56.3 & 9.4 & 15.6 & 9.4 & 31.3 & 21.9 \\
\hline \multirow{3}{*}{$\begin{array}{l}\text { Cleaning } \\
\text { teeth material }\end{array}$} & Tooth paste & 65.6 & 96.9 & 43.8 & 87.5 & 68.8 & 78.1 & 68.8 & 78.1 \\
\hline & Salt & 12.5 & 0 & 0 & 0 & 6.3 & 6.3 & 12.5 & 15.6 \\
\hline & Others & 21.9 & 3.1 & 56.3 & 12.5 & 25 & 15.6 & 18.8 & 6.3 \\
\hline \multirow{5}{*}{$\begin{array}{c}\text { Frequency of } \\
\text { cleaning } \\
\text { at day }\end{array}$} & 1 time & 25 & 18.8 & 15.6 & 25 & 21.9 & 28.1 & 28.1 & 25 \\
\hline & 2 time & 18.8 & 46.9 & 9.4 & 31.3 & 21.9 & 31.3 & 18.8 & 31.3 \\
\hline & 3 time & 6.3 & 15.6 & 6.3 & 15.6 & 9.4 & 15.6 & 15.6 & 15.6 \\
\hline & Infrequent & 43.8 & 15.6 & 12.5 & 18.8 & 31.3 & 15.6 & 6.3 & 6.3 \\
\hline & Never & 6.3 & 3.1 & 56.3 & 9.4 & 15.6 & 9.4 & 31.3 & 21.9 \\
\hline \multirow{3}{*}{$\begin{array}{l}\text { Time period } \\
\text { of cleaning }\end{array}$} & $<1$ minute & 53.3 & 22.6 & 35.7 & 27.9 & 55.6 & 34.5 & 31.8 & 24 \\
\hline & $1-2$ minutes & 30 & 71 & 35.7 & 51.7 & 37 & 48.3 & 40.9 & 48 \\
\hline & $>2$ minutes & 16.7 & 6.5 & 28.6 & 20.7 & 7.4 & 17.2 & 27.3 & 28 \\
\hline \multirow{3}{*}{$\begin{array}{c}\text { Preferable } \\
\text { time of clean- } \\
\text { ing }\end{array}$} & Before breakfast & 41.7 & 32.6 & 47.1 & 30.8 & 44.1 & 33.3 & 32.1 & 34.3 \\
\hline & At bed time & 52.8 & 56.5 & 41.2 & 56.4 & 47.1 & 53.8 & 50 & 51.4 \\
\hline & After each meal & 5.6 & 10.9 & 11.8 & 12.8 & 8.8 & 12.8 & 17.9 & 14.3 \\
\hline \multirow{3}{*}{$\begin{array}{l}\text { Brushing } \\
\text { techniques }\end{array}$} & Horizontal & 75 & 24.2 & 71.4 & 34.5 & 74.1 & 36.7 & 54.5 & 20 \\
\hline & Vertical & 21.4 & 45.5 & 28.6 & 51.7 & 25.9 & 53.3 & 45.5 & 72 \\
\hline & Circular & 3.6 & 30.3 & 0 & 13.8 & 0 & 10 & 0 & 8 \\
\hline \multirow{3}{*}{$\begin{array}{l}\text { Change of } \\
\text { tooth brush }\end{array}$} & 2-3 months & 53.6 & 74.2 & 71.4 & 72.4 & 62.5 & 70.4 & 63.6 & 68 \\
\hline & 4-5 months & 10.7 & 16.1 & 14.3 & 20.7 & 8.3 & 14.8 & 27.3 & 28 \\
\hline & $>6$ months & 35.7 & 9.7 & 14.3 & 6.9 & 29.2 & 14.8 & 9.1 & 4 \\
\hline \multirow{3}{*}{$\begin{array}{l}\text { Reason of } \\
\text { tooth brush- } \\
\text { ing }\end{array}$} & $\begin{array}{c}\text { Remove food debris and } \\
\text { bacteria }\end{array}$ & 62.5 & 90.6 & 57.1 & 89.7 & 78.1 & 81.3 & 58.8 & 73.5 \\
\hline & Teeth whitening & 15.6 & 6.3 & 19 & 5.1 & 6.3 & 15.6 & 17.6 & 11.8 \\
\hline & I don't know & 21.9 & 3.1 & 23.8 & 5.1 & 15.6 & 3.1 & 23.5 & 14.7 \\
\hline \multirow{3}{*}{$\begin{array}{l}\text { Dental floss } \\
\text { using }\end{array}$} & Daily & 3.1 & 25.8 & 0 & 9.4 & 0 & 9.4 & 0 & 12.5 \\
\hline & Weekly & 12.5 & 29 & 15.6 & 53.1 & 12.5 & 40.6 & 18.8 & 18.8 \\
\hline & Never & 84.4 & 45.2 & 84.4 & 37.5 & 87.5 & 50 & 81.3 & 68.8 \\
\hline
\end{tabular}

\section{REFERENCES}

1. Towner E. The history of dental health education: a case study of Britain. In: Schou L, Blinkhorn A, editors. Oral Health Promotion. Oxford: Oxford University Press, 1993.

2. Murray JJ, Nunn JH, Steele JG. Prevention of oral disease, $4^{\text {th }}$ ed. Oxford: Oxford University, 2003; 7-34, 77-95, 123144, 241-258.

3. Overton DA, Mason J. Community oral health education concept in dental public health. Philadelphia: Lippincott Williams and Wilkins, 2005; 139-157.

4. Bazile A, Bissada NF, Nair R, Siegel B. Perio-dontal assessment of patients undergoing an-gioplasty for treatment of coronary artery dis-ease. J Periodontol. 2002; 73: 631-636.

5. Ylöstalo PV, Järvelin MR, Laitinen J, Knuuttila ML. Gingivitis, dental caries and tooth loss: risk factors for cardiovascular diseases or indicator of elevated health risks. J Periodontol. 2006; 33: 92-101.

6. Horowitz AM, Kleinman DV. Oral health literacy: The new imperative to better oral health. Dent Clin N Am. 2008; 52: 333-344.

7. Pine CM. Designing school programmes to be effective vehicles for changing oral hygiene behavior. Int Dent $\mathrm{J}$. 2007; 57: 377-381.

8. Jürgensen N, Petersen PE. Promoting oral health of children through schools-Results from a WHO global survey 2012. Community Dental Health. 2013; 30:204-218.

9. Matsson L. Factors influencing the susceptibility to gingivitis during childhood-a review. Int J Paediatr Dent. 1993; 3(3):119-127.

10. Damle SG. Pediatric dentistry, 4th ed. Arya (MEDI) Publishing House-New Delhi, 2012. 
11. Rong WS, Bian JY, Wang WJ, Wang JD. Effectiveness of an oral health education and caries prevention program in kindergartens in china. Community Dent Oral Epidemial. 2003; 31(6):412-416.

12. Vonabbergen J, Declerck D, Mwalili S, Martens L. The effectiveness of a 6 year oral health education programme for primary school children. Community Dent Oral Epidemial .2004, Apr; 32(2):143-149.

13. Sarnat H, Arad P, Hanauer D, Shohami E. Communication strategies used during pediatric dental treatment: a pilot study. Pediatr Dent. 2001; 23(4):337-342.

14. Petersen PE. The World Oral Health Report: Continuous improvement of oral health in the $21^{\text {st }}$ century-the approach of the WHO Global Oral Health Programme. Community Dent Oral Epidemiol 2003; 31(Suppl. 1):13-24.

15. WHO. Oral Health Surveys-Basic Methods, $4^{\text {th }}$ ed. Geneva: World Health Organization.1997.

16. Daly B, Watt R, Batchelor P, Treasure E. Essential Dental Public Health. Oxford: Oxford University, 2005; 133-152.

17. Chapman A, Copestake SJ, Duncan K. An oral health education programme based on the National Curriculum. Int J Paediatr Dent. 2006; 16:40-44.

18. Zimmers, Bizhang M, Seemann R, Barthel CR. Effective of preventive programs on oral hygiene at adults and school children . Przegl lek. 2004; 61(8): 880-883.

19. Bankole OO, Ibiyemi O, Oke GA. A dental health education video for Nigerian children in the Yoruba Language. Afr. J. Biomed. Res. 2011; 14(1): 77-79.

20. Kay E, locker D. A Systematic review of the effectiveness of health promotion aimed at improving oral health.
Community Dent Health 1998 Sep; 15(3):132-44.

21. Astrom AN, Okullo I. Validity and reliability of oral impacts on daily performance (OIDP) frequency scale: a cross sectional study of adolescent in Uganda. BMC Oral Health. 2003; 3(1):5.

22. Griffiths J, Boyles. Colour guide to holistic oral care: A practical approach. Mosby-yearbook Europe, BPCC, 1993; 42.

23. Biesbrock AR, Walter PA, Bartizek RD. Initial impact of a national dental education program on the oral health and dental knowledge of children. J Contemp Dent Pract. 2003; 2(4):1-10.

24. Naaom ER. Effect of preventive periodontal health education on the oral hygiene of primary school children. MDJ. 2009; 6(4):402-407.

25. Hussain SR. Effectiveness of dental health education program on periodontal health status of nursery school children in Erbil city. Zanco J. Med. Sci. 2012; 16(3):175179.

26. Liana Bastos, Arthur Belem, Alfredo Carlos. Effectiveness of an Oral Hygiene Program for Brazilian Orphans. Braz Dent J. 2002; 13(1): 44-48.

27. Baggio MA, Erdmann AL, Dal Sasso GTM. Cuidado humano e tecnologia na enfermagem contemporânea e complexa. Texto \& contexto enferm. 2010; 19(2):378-85.

28. Stina APN, Zamarioli CM, Carvalho EC. Effects of an educational video on the oral hygiene of patients with hematologic disorders. Rev. Eletr. Enf. .2014; 16(2):304411. 